\title{
Understanding Precipitate Evolution During Friction Stir Welding of Al-Zn-Mg-Cu Alloy Through In-situ Measurement Coupled With Simulation
}

\author{
J. F. dos Santos ${ }^{\mathrm{a}}$, P. Staron ${ }^{\mathrm{a}}$, T. Fischer ${ }^{\mathrm{a}}$, J. D. Robson ${ }^{\mathrm{b}, *}$, A. Kostka ${ }^{1 \mathrm{c}}$, \\ P. Colegrove ${ }^{\text {d }}$, H. Wanga,d, J. Hilgert ${ }^{\mathrm{a}}$, L. Bergmann ${ }^{\mathrm{a}}$, L. L. Hütsch ${ }^{\mathrm{a}}$, \\ N. Huber ${ }^{a}$, A. Schreyer ${ }^{2 a}$ \\ ${ }^{a}$ Helmholtz-Zentrum Geesthacht, Institute of Materials Research, Materials Mechanics, \\ Max-Planck Str. 1, 21502, Geesthacht, Germany \\ ${ }^{b}$ School of Materials, University of Manchester, Oxford Road, Manchester M13 9PL, UK \\ ${ }^{c}$ Max-Planck-Institut für Eisenforschung GmbH, Dpt. Microstructure Physics and Alloy \\ Design, Max-Planck-Str. 1, 40237 Düsseldorf, Germany \\ ${ }^{d}$ Welding Engineering Research Centre, Cranfield University, Cranfield, MK23 0AP, UK
}

\begin{abstract}
Friction Stir Welding (FSW) imparts both heat and deformation to the metal being joined, producing profound microstructural changes that determine the weld properties. In the case of welding of aerospace aluminium alloys, the most important change is the modification of the size, nature, and fraction of strengthening precipitates. To understand these changes requires the ability to measure the microstructural evolution during the welding process. This paper describes a new tool, the FlexiStir system, a portable friction stir unit designed for use in a high-energy synchrotron beamline that enables in-situ studies of microstructural evolution during FSW. FlexiStir has been used to measure precipitate evolution during FSW of aluminium alloy 7449-TAF and provide time-resolved measurement of precipitate size and volume fraction via small angle X-ray scattering (SAXS). These measurements have been interpreted with the aid of a previously developed microstructural model. The

\footnotetext{
${ }^{*}$ Corresponding author, Prof Joseph D Robson, + 44-161-3063560

Email address: joseph.robson@manchester.ac.uk (J. D. Robson)

${ }^{1}$ Present address: Materials Research Department and Center for Interface Dominated

${ }^{2}$ Present address: European Spallation Source ERIC, Director for Science, Box 176,
} Materials (ZGH), Ruhr-University Bochum, Germany S-221 00, Lund, Sweden
\end{abstract}


model predictions and SAXS measurements are in good qualitative agreement and demonstrate the complex precipitate transformation, dissolution, and reprecipitation events that occur during welding.

Keywords: Al alloy, friction stir welding, precipitation kinetics, numerical modeling, small-angle X-ray scattering

\section{Introduction}

Friction stir welding (FSW) was developed and patented in 1991 [1] and is considered a solid state joining technique in which no bulk melting of the base material occurs. The process relies on the frictional heating and shear strain induced by a rotating, non-consumable tool, consisting of a probe and a shoulder [2]. During FSW, the rotating tool is plunged into the work pieces, plasticizes the material underneath the tool and is subsequently traversed along the interface between the materials which are to be joined. The still solid, but highly deformed material, flows around the tool, forming a consolidated joint behind it [3]. The side of the workpiece where the tool rotation and translation are in the same direction is named the "advancing side", while the opposite is the "retreating side".

The heat and deformation that accompany welding lead to profound microstructural changes. FSWs in Al alloys generally result in three microstructural zones: The center of the joint is characterized by the stir zone (SZ) in which the severe plastic deformation leads to dynamically recrystallized grains with a process temperature dependent grain size [4]. In addition, this material is exposed to the highest temperatures, which in precipitate (age) hardenable alloys can lead to complete dissolution of the strengthening precipitates $[5,6]$. The stir zone is typically surrounded by a partly recrystallized, partly recovered microstructure, which is affected by lower levels of deformation and temperature in comparison to the SZ and is referred to as the thermo-mechanical affected zone (TMAZ). The precipitates in the TMAZ may be fully or partially dissolved, and surviving precipitates may transform and coarsen depending on the temperature and time of exposure. The neighbouring region, which is affected only by the thermal cycle, is denoted the heat affected zone (HAZ) [7]. In this zone, precipitates are coarsened and may transform from metastable to equilibrium phases.

These complex microstructural changes lead to strong property variations across the weld. This is further complicated because age hardenable 
aluminium alloys exposed to high enough temperature can recover some of their strength during holding at room temperature due to natural ageing effects. This effect is strongest in regions where the solute level in the matrix is highest, and this corresponds to SZ, where the highest temperatures are reached. Thus, the SZ hardness (and strength) can often recover from a low level in the as-welded state to a level approaching the initial hardness after several months natural ageing. This means that after even only a short period of natural ageing, the SZ is normally stronger than the TMAZ or HAZ material, where the potential for natural ageing is less. After natural ageing, this leads to a characteristic "W" shape in the cross-weld hardness profile, with the hardness minimum usually observed at the HAZ/TMAZ border, where the overaging is most severe but insufficient solute is available for strong post-weld natural ageing $[5,6]$.

To understand these complex phenomena, there has been an extensive effort to characterize post-weld microstructures and also to develop physical models to simulate the microstructural evolution during the FSW process $[2,10,11]$. This is particularly true for $\mathrm{Al}-\mathrm{Zn}-\mathrm{Mg}-\mathrm{Cu}(7 \mathrm{xxx})$ alloys, where FSW is a promising technology for aerospace applications. Multiscale models that couple together a prediction of the process $[8,9]$, linked to microstructure $[10,11]$, and finally to property prediction $[10,12]$ have been created for this system and used to help understand the microstructural processes and the influence of key welding parameters (such as tool travel and rotation speed). However, testing and validating such models is difficult and timeconsuming. This is for two key reasons: Firstly, it is only practical to perform microscopy at the scale needed to study precipitates on a small number of very local regions of microstructure (via transmission electron microscopy, TEM). Secondly, it is not possible to measure the transient microstructural evolution during the welding process using conventional (ex-situ) techniques.

The work presented here addresses these issues by using a novel in-situ method to track microstructural evolution over large volumes of material (relative to TEM), collecting data during the welding process to study the dynamic, transient, behaviour as the tool passes through the material. To make this possible has required developing a new, highly controllable welding system (FlexiStir) that is capable of being mounted in a synchtron X-ray beamline, permitting fast capture of microstructural information via small angle X-ray scattering (SAXS). SAXS has previously been shown capable of characterizing the precipitate volume fraction and size in FSWs of 7xxx aluminium alloy [6]. However, previous studies have been limited to ex-situ 
analysis, and this work represents the first time this method has been used to track precipitate evolution during welding in-situ.

The FlexiStir system can provide hitherto inaccessible data on microstructural (specifically precipitate) evolution during the welding process systematically across all the weld zones. In this paper, the FlexiStir system was applied to measure precipitate evolution during FSW of AA4779-TAF. These measurements have been compared with predictions of a model for this system, and used to identify the key areas for improvement of the model. Together, the in-situ measurements and model predictions provide new insights into the FSW of 7xxx aluminium alloys.

\section{Experimental}

The alloy under investigation in the present study is the precipitation hardenable Al alloy AA7449. It has been selected for this investigation due to its relevance to aircraft performance, since it is extensively used in wing structures. The alloy is in a TAF (temper for age-forming) temper. In this condition the material is "underaged" (aged to below peak strength), and is designed so that the final overaged temper condition is reached during the age-forming process that would follow welding in application. The nominal chemical composition of the alloy is given in Table 1 .

\begin{tabular}{|ccccccc|}
\hline $\mathrm{Cu}$ & $\mathrm{Mg}$ & $\mathrm{Si}$ & $\mathrm{Fe}$ & $\mathrm{Mn}$ & $\mathrm{Zn}$ & $\mathrm{Al}$ \\
\hline 1.80 & 2.03 & 0.05 & 0.08 & $<0.01$ & 8.36 & $\mathrm{Bal}$. \\
\hline
\end{tabular}

Table 1: Chemical composition (in wt.\%) of aluminium alloy 7449-TAF.

The friction stir welding was performed using the FlexiStir system, a unique machine which has been developed with the aim of performing insitu synchrotron X-ray scattering experiments during welding operations. The system consists of six controlled actuators and one manually adjustable axis. The controller allows the sample table to be moved in such a way that measurements can be made at a fixed position with respect to the either the tool or workpiece. The tool position is fixed with respect to the beamline and the workpiece is translated during welding; thus, measurements were carried out at fixed positions with respect to the tool. A diagram illustrating the experimental set up is presented in Figure 1. 
The spindle motors deliver $20 \mathrm{Nm}$ torque over a rotation speed range of 0-3000 RPM, with maximum axial force of $40 \mathrm{kN}$. In the present study, the anvil of the FSW unit, which is necessary to counteract the forces produced by the process, contained a $3 \mathrm{~mm}$ wide slit as a window for the X-ray beam. The slit was covered by a 1.5 -mm-thick copper inlet to prevent material from being extruded through the slit during welding. For sufficient statistics, the exposure time for X-ray collection was set to $10 \mathrm{~s}$. During this time, the position of the X-ray beam was held constant with respect to the FSW tool, while the workpiece was moved forward. All the experiments were carried out on $3.2 \mathrm{~mm}$-thick sheets of $\mathrm{Al}$ alloy AA7449-TAF, using a rotational speed of $1300 \mathrm{RPM}$ and welding speeds that varied from $2-8 \mathrm{~mm} \mathrm{~s}^{-1}$.

The welding experiments were carried out utilising the high-energy beam line HARWI II of the Helmholtz-Zentrum Geesthacht, located at the former DORIS III synchrotron storage ring at DESY, Hamburg, Germany[12]. The sample table of the machine was inclined to $57^{\circ}$ during the in-situ welding experiments, such that the X-ray beam was able to pass next to the tool shoulder.

To penetrate $3.2 \mathrm{~mm}$ of the $\mathrm{Al}$ alloy in addition to $1.5 \mathrm{~mm}$ of a $\mathrm{Cu}$ backing sheet, a high photon energy is required. The measurements in the present study were performed using $70 \mathrm{keV}$ photons, giving a transmission of $70 \%$ for AA7449. The transmission of the $\mathrm{Cu}$ backing sheet was $20 \%$, giving a total transmission of $14 \%$. One advantage of such a high photon energy is that no vacuum is required, and the experiment can be performed in air. The disadvantage is that the $2 \theta$ scattering angles are very small, and the range of covered scattering vectors $q=4 \pi \sin \theta / \lambda$ is limited to the small- $q$ end of the scattering curve ( $\lambda$ is the photon wavelength, which can be calculated from the photon energy $E$ by $\lambda=12.398 / E$, where $\lambda$ is in $\AA$ and $E$ is in $\mathrm{keV})$. The scattering vectors covered by the experimental set-up range from $0.13 \mathrm{~nm}^{-1}$ to $4.3 \mathrm{~nm}^{-1}$.

The program Fit2d [13] was used for the data reduction. The variation in the beam intensity was corrected according to the signal of a beam monitor. The background signal, without a sample in the beam, was dominated by the scattering of the $\mathrm{Cu}$ backing sheet; this signal was subtracted from the raw scattering data. No calibration to absolute intensities was performed. The scattering signal had rotational symmetry; thus, all images were integrated along the azimuth to yield the scattering curves. The scattering curves were fitted using a two-phase model of precipitates embedded in a homogeneous matrix, leading to the macroscopic scattering cross section of: 


$$
\frac{d \Sigma}{d \Omega}(q)=(\Delta \eta)^{2} \int_{0}^{\infty} n(R) V(R)^{2} F(q, R)^{2} d R+A q^{-4}+B
$$

where $\Delta \eta$ is the scattering contrast given by the difference in the electron density between the matrix and the precipitate, $n(R) d R$ is the number density of particles in the radius interval $d R, V(R)$ is the particle volume, and $F(q, R)$ is the particle form factor. A single lognormal size distribution was used for $n(R)$. The total particle volume fraction $f$ is obtained as the integral of $n(R) V(R)$ over the size distribution. The second term accounts for a contribution from larger structures, which scatter into the measured $q$-range with a $q^{-4}$-tail. The constant $B$ accounts for the isotropic background. The fitting was carried out using a least-squares minimisation algorithm. Because no absolute cross sections were determined, the volume fraction $f$ was calibrated by the known volume fraction of the precipitates in the base material. A spherical shape was assumed for the precipitates, and the corresponding form factor was used. The mean particle radius was calculated from the volume fraction distribution. The mean particle radius of the particles was calculated with the respect to their spherical shape.

In the SAXS experiments, the X-ray beam was monochromated by a $\mathrm{Si} / \mathrm{Ge}$ gradient monochromator for highest flux. The beam size, defined by tungsten slits, was approximately $0.2 \mathrm{~mm} \times 0.2 \mathrm{~mm}$. A Mar 345 image plate with a pixel size of $150 \mu \mathrm{m}$ was used as the area detector at a distance of $7 \mathrm{~m}$ from the sample. A lead beam stop was placed between the sample and the detector to absorb the direct beam. In the SAXS experiment, the particle distribution is determined by measuring scattering though the whole specimen thickness. In thin sheet (as studied here) there is expected to be only minor variation in particle distribution through the thickness.

To validate the SAXS results and provide more details of the precipitates within the microstructure, scanning transmission microscopy (STEM) was performed at selected regions across the weld corresponding to the SZ, TMAZ and HAZ. The STEM microstructural analysis was conducted on a JEOL JEM-2200FS operating at $200 \mathrm{kV}$. The sample preparation consisted of the mechanical grinding of $3 \mathrm{~mm}$ discs to $120 \mu \mathrm{m}$ in thickness followed by electropolishing. A Struers Tenupol-3 was used for the electropolishing process, operated at $12 \mathrm{~V}$ with a solution composed of $1 / 3$ nitric acid and $2 / 3$ methanol cooled to $-30^{\circ} \mathrm{C}$. 


\section{Model}

The model used in this work consists of two key components; a process model that describes the welding process, and a microstructure model that predicts the effect of the thermal and deformation cycle on precipitate and grain structure evolution. Full details of both the process [14] and microstructural model $[11,12]$ are given elsewhere. The essential points are summarized here.

The process model is a based on a computational fluid dynamics (CFD) framework and is implemented in FLUENT ${ }^{\mathrm{TM}}$ [14]. The deforming solid material is modelled as a fluid with high viscosity, whose properties are dependent on both the temperature and the strain rate. Material properties as a function of temperature and strain rate were determined from the highspeed compression tests performed at temperatures approaching the solidus. This model has shown a good ability to predict the temperature field from the process parameters once the material properties and thermal coefficients have been correctly chosen [14]. Figure 2 shows good agreement between the model-predicted and the thermocouple-measured thermal profiles for the weld performed at $5 \mathrm{~mm} \mathrm{~s}^{-1}$ travel speed. Similar agreement was found for all welding speeds.

The microstructural model takes the outputs from the process model (temperature, strain rate, strain) as its inputs. The model explicitly tracks the three distinct precipitate populations present in AA7449. These phases are the grain interior metastable $\eta^{\prime}$, the grain interior equilibrium $\eta$, and the grain boundary $\eta[11,12]$. The predictions can assist in interpreting the in-situ data because the contribution of each individual phase to the overall volume fraction and radius can be isolated. The present modelling approach is based on classical kinetic theory and is an extension of the Kampmann and Wagner numerical (KWN) method [15]. The effect of the grain refinement that occurs in the stir zone on the precipitate evolution is also considered [16]. Full details of the model are given elsewhere $[11,12,16]$, but a summary of its key points is given below.

In the KWN method, the particle size distribution for each precipitate type is discretized into a large number of size classes. In the present case, there are three distinct precipitate populations (grain interior metastable $\eta^{\prime}$, grain interior equilibrium $\eta$, and grain boundary $\eta$ ) each of which has its own size distribution. The temporal evolution of the size classes is divided into

small time-steps. At each time-step, the number of new particles of each type 
is calculated using classical nucleation theory, and these particles are added into the size distribution at a size slightly larger than the critical radius [15].

The growth or shrinkage of particles is calculated for each size class. A growth law appropriate to the type of precipitate is used; grain interior precipitates are treated as spheres undergoing diffusion controlled growth. Grain boundary precipitate growth is modeled using a collector plate growth law developed by Carolan and Faulkner [17]. For the purposes of calculating growth rate, the alloy is approximated as an $\mathrm{Al}-\mathrm{Zn}-\mathrm{Mg}$ ternary system. This introduces an additional degree of freedom over a binary system and requires an additional constraint to solve the growth equation. In the present model, the growth rate equations are solved under the constraint that the interfacial compositions must satisfy both local equilibrium and flux balance to give the correct precipitate stoichiometry. A solubility product approach is used to account for the effect of capillarity on the interfacial composition [11]. Both the $\eta^{\prime}$ and $\eta$ precipitates are assumed to have an idealized exact stoichiometry $\left(\mathrm{MgZn}_{2}\right)$ and the incorporation of $\mathrm{Al}$ or $\mathrm{Cu}$ into these phases is ignored [18]. Although this is not accurate, the model predictions are not very sensitive to this parameter [11]. Once the growth rate is known for each size class, the particles are redistributed appropriately between size bins, as described elsewhere [19]. An accuracy check (based on the Runge-Kutta method) is used to adapt the value of the time-step between iterations to an appropriate value.

The three precipitate populations interact in a number of ways. The first interaction is through the competition for solute. Grain boundary precipitation removes solute from the region adjacent to the grain boundary, which leads to a precipitate free zone (PFZ). This is modeled by considering a distinct PFZ zone, with its own matrix solute level, which evolves as grain boundary precipitates form or dissolve [11, 12]. Grain interior precipitates compete for solute; in the KWN method, a mean field approach is used to calculate the remaining solute level in the matrix accounting for the solute removed into all precipitate populations $\left(\eta^{\prime}\right.$ and $\left.\eta\right)$. Solute is exchanged between the grain interior and grain boundary zones at each time-step, driven by the concentration gradient.

The second important interaction between precipitate populations is the transformation of metastable $\eta^{\prime}$ to equilibrium $\eta$. Experimental observations suggest this occurs via an in-situ transformation mechanism that takes place once the $\eta^{\prime}$ reaches a critical particle size [20]. Therefore, in the present model, $\eta^{\prime}$ particles that grow into a size class that is larger than the critical 
size are removed from the $\eta^{\prime}$ population and are added to the $\eta$ population (at the same size). The critical size is (linearly) temperature dependent, being smaller at higher temperature. Once a temperature of $300^{\circ} \mathrm{C}$ is reached, it is assumed that all the $\eta^{\prime}$ transforms to $\eta$.

The critical size is one of the parameters in the model that is calibrated against experimental data. The other key calibration parameters are the effective interfacial energies for each of the precipitate types and grain boundary diffusion coefficients. These parameters were determined using isothermal and ramp-heating experiments using a combination of calorimetry, small angle X-ray scattering, and microscopy to quantify the microstructural evolution. Details of the calibration process are given elsewhere [11, 12].

The KWN method naturally accounts for precipitation, growth, and coarsening; which of these processes will dominate depends on the solute level remaining in the matrix [15]. Application of the model to welding is straightforward, since at each time-step the temperature can be changed to track the thermal cycle of welding. The adaptive time-step routine is essential to ensure accuracy, since the microstructure can change very rapidly during the high temperature part of the weld cycle, but very slowly towards the end of post-weld cooling.

For friction stir welding, there is an additional complication due to the deformation induced during the welding process. One of the main effects of deformation is to greatly refine the grain size in the stir zone, and thus produce a large increase in the grain boundary area available for grain boundary precipitation. This is accounted for by including a simple grain refinement model based on the idea that geometric dynamic recrystallization (gDRX) controls the initial stir zone grain size $[21,16]$. Grain growth behind the tool is then accounted for using a simple grain-growth law where the effect of precipitation on boundary mobility is considered through a Zener pinning equation. It has been previously been demonstrated that the final grain size is determined largely by the grain growth that occurs behind the tool, and precipitation may limit the maximum grain size reached $[21,16]$. A full description and justification for this approach is given elsewhere [16]. The other effect of deformation can be a direct influence on dissolution and precipitation kinetics due to deformation induced vacancies and dislocations. However, the effect of temperature on these processes is overwhelming, and the most rapid microstructural change occurs at temperatures above approximately $450^{\circ} \mathrm{C}$, where recovery processes in aluminium alloys are very fast. It has also previously been demonstrated that microstructure models based 
on thermal effects alone can capture the precipitate evolution and resultant effect on strength (hardness) to reasonable accuracy, across a range of weld conditions $[2,10,11,12]$. Direct deformation effects are therefore ignored in the model. This simplifies the highly complex problem of coupled thermomechanical exposure but at the expense of accuracy, especially in the TMAZ where a high excess dislocation density can be maintained.

The required inputs to the model are the alloy chemistry, the thermodynamic properties of the precipitate phases, and the thermal and deformational history experienced as a function of the position across the weld. The initial precipitate population is also required, and this can be either predicted (running the model to simulate the temper state) measured experimentally. In the present study, experimental measurements (STEM) of the particle size distributions for grain boundary and grain interior precipitates in the base metal were used to initialize the model. The initial grain interior precipitate population was assumed to be fully $\eta^{\prime}$, and the grain boundary precipitates were assumed to be $\eta$, as expected for the TAF temper state and consistent with previous work [5].

The required thermal and material flow information is extracted from the CFD process model described previously. The thermodynamic properties of the equilibrium and metastable phases were calculated using JMatPro, a Calphad based thermodynamic software package, using the ALDATA thermodynamic database.

\section{Results and Discussion}

\section{1. $S A X S$}

Two distinct datasets were captured using the FlexiStir system. The dynamic precipitate evolution in the region behind the tool on the advancing side of the weld (see Figure 1) was measured at the reference welding speed of $5 \mathrm{~mm} \mathrm{~s}^{-1}$, and maps showing the measured volume fraction and mean radius for this region are presented in Figure 3. These maps show an increase in precipitate volume fraction behind the tool caused by re-precipitation of solute as the weld cools. There is also an increase in reprecipitated volume fraction in moving from the centerline position towards the edge of the shoulder. The mean radius of particles in the detected range was found to decrease from the weld center, but to remain approximately constant with increasing distance behind the tool over the range of positions measured. 
These results confirm that reprecipitation occurs behind the tool and show that the amount of reprecipitation varies significantly with position. The balance of reprecipitated and retained solute will determine the potential for natural ageing after welding. Further interpretation of these results is difficult for two reasons; firstly, the limited range of particle sizes that can be captured by the SAXS configuration used in the present work (0-20 nm) and secondly because it is not possible to sample directly under the tool where the microstructure is changing most rapidly. However, in combination with the model, it is possible to address these issues and make further inferences from these observations. Therefore, a full explanation of these results also requires a consideration of the model predictions, as discussed later.

The second data-set was captured as a lateral scan in the HAZ perpendicular to the tool (as shown in Figure 1). These measurements correspond to the microstructural state obtained when the material in the HAZ is close to its maximum temperature (as the tool center passes). They thus give a unique insight into the volume fraction of precipitates in the HAZ that survive from the initial condition. Such data are impossible to obtain by ex-situ analysis, since post weld cooling will lead to further microstructural modification (e.g. reprecipitation). The loss of precipitates in the useful size range for strengthening causes "microstructural damage" that leads to a loss of strength in the HAZ (which often limits to the overall weld performance). These measurements were performed for welding speeds ranging from 2$8 \mathrm{~mm} \mathrm{~s}^{-1}$, enabling the effect of travel speed on microstructural damage in the HAZ to be determined.

Figure 4 shows the measured volume fraction as a function of lateral distance for the welding speeds studied. It can be seen that for all speeds, the lowest volume fraction is closest to the shoulder, and in all cases is between $15-35 \%$ of the initial precipitate volume fraction (which is $4.7 \%$ ). As the distance from the shoulder increases, the difference in welding speed becomes more apparent. At the fastest speed $\left(8 \mathrm{~mm} \mathrm{~s}^{-1}\right)$ the retained volume fraction increases strongly with distance, whereas for the slowest welding speed, the volume fraction remains at $15-35 \%$ of the initial value across the full distance studied.

These observations are consistent with the effect of welding speed on the thermal field. For the slower welding speeds, there is sufficient time for heat to travel further from the tool, and so more precipitate dissolution occurs at greater distances from the centerline. At the fastest speed, the peak temperature reached falls off rapidly with distance, and so therefore does the 
amount of precipitate dissolution. Further details of the likely microstructural changes in this region are discussed later in the light of the model predictions.

\subsection{STEM}

Low magnification images of the overall microstructure of the FSWs reported here showed features that were similar to those observed previously in welding of this alloy $[5,6]$ and are not repeated here. However, microscopy was required to validate the results of the SAXS measurement, and for this purpose high resolution images were acquired to accurately determine the precipitate size distributions in each of the weld zones.

Observations of typical precipitate distributions for the different weld zones (base material, stir zone, and TMAZ), as identified by high angle annular dark field (HAADF) STEM imaging, are shown in Figure 5. The microstructure of the base material is characterised by a large amount of uniformly distributed; small precipitates of several $\mathrm{nm}$ in diameter (Figure 5 (a)). In the initial temper state of the present material (underaged, TAF) these precipitates are expected to be mainly $\eta^{\prime}$ [5]. The grain boundaries are decorated with slightly larger particles, ranging to $30 \mathrm{~nm}$ in diameter, which are expected to be $\eta$-phase. The TMAZ reveals a distribution of larger plate shaped precipitates with reduced number density, which are expected to be $\eta-$ phase, with the metastable $\eta^{\prime}$ in the parent either dissolving or transforming to $\eta$ depending on the particle size.

The SZ reveals a more complex bimodal particle distribution, with a population of larger particles (up to approximately 50nm in diameter) coexisting with small (nm scale) particles. This type of structure has been previously observed in AA7449 friction stir welds [5], with the larger particles identified as $\eta$ phase precipitated on the refined high angle grain boundaries during the initial stages of post-weld cooling, and the smaller particles being $\eta$ or $\eta^{\prime}$ precipitates formed within the grains or on sub-grain boundaries later during the cooling process. In the present case, many of the smaller particles are aligned suggesting they have precipitated on subgrain boundaries or individual dislocations. Many of the larger particles are not located on the grain boundaries, but are found inside the grains. However, this does not mean the larger particles were not nucleated initially at the grain boundaries, since extensive grain growth is known to occur in the region immediately behind the pin $[21,16]$. It is thus plausible that the larger particles were nucleated on grain boundaries as the weld cooled, but the pinning they provided 
was insufficient to prevent further migration of the boundary away from the particle.

\subsection{Microstructural Model}

\subsubsection{Comparison of Model to SAXS data}

The model calibration is described in detail elsewhere $[11,12]$ and is undertaken using isothermal and ramp heat treatments. No further calibration or alteration of the calibrated parameters (e.g. interfacial energies of the precipitate phases) was made in this work. Dynamic effects are significant in the SZ, since the refined grain size provides additional nucleation sites for formation of grain boundary $\eta$ phase on cooling. The importance of this coupling to precipitation during FSW of AA7449 is discussed in detail elsewhere [22]. If grain refinement in the $\mathrm{SZ}$ is ignored, then very little grain boundary precipitation is predicted on post-weld cooling and as a result there is sufficient supersaturation for extensive quench induced precipitation in the grain interiors. Accounting for grain refinement, it is predicted that grain boundary $\eta$ precipitates first in the SZ, removing solute and suppressing the formation of quench induced precipitates in the grain interior [22].

The predicted evolution of the volume fraction of the precipitate phases is shown in Figure 6 at increasing distance from the weld centerline (a-d) for a welding speed of $5 \mathrm{~mm} \mathrm{~s}^{-1}$. The $x$-axis of these plots is the position along the welding direction with respect to the tool; zero corresponds to the tool center, negative positions are ahead of the tool and positive positions are behind the tool.

The initial microstructure (base metal), as characterized by SAXS and STEM, consists of $\eta^{\prime}$ precipitates within the grains and a small volume fraction of grain boundary $\eta$ phase. Figure $6(\mathrm{a})$ and (b) correspond to positions at the weld centerline and $2 \mathrm{~mm}$ from the centerline (respectively); in both cases this material has been directly stirred by the tool and has seen similar a thermomechanical history. A complex sequence of microstructural changes is predicted, which is similar for both positions shown in (a) and (b). The volume fraction change becomes significant once the temperature exceeds $170^{\circ} \mathrm{C}$, which occurs $7 \mathrm{~mm}$ ahead of the tool center, and the microstructure is predicted to continue to evolve until the material falls back below this temperature after welding, at a position $15 \mathrm{~mm}$ behind the weld center.

To see in more detail the changes that occur in the SZ, Figure 7 is a zoomed-in plot for the weld centerline position, showing only the range of positions nearest to the tool. The first predicted change to occur is the 
transformation of metastable $\eta^{\prime}$ phase to $\eta$. At a position $5 \mathrm{~mm}$ ahead of the tool center, it is predicted that all of the $\eta^{\prime}$ has either dissolved or transformed to $\eta$, which will then grow. On continued heating, the $\eta$ precipitates will themselves become unstable and begin to dissolve (at $3.5 \mathrm{~mm}$ ahead of the tool center). There is predicted to be a very small amount of grain boundary precipitation, driven by the solute released as the $\eta$ phase dissolves, but these precipitates do not become well established, and rapidly dissolve as heating continues. At the peak temperature, the newly formed $\eta$ is also unstable and dissolves.

On cooling behind the tool, the matrix is now heavily supersaturated in the age hardening elements $(\mathrm{Zn}, \mathrm{Mg}, \mathrm{Cu})$. It is predicted that this leads to reprecipitation of grain boundary $\eta$ phase, starting at a position $2 \mathrm{~mm}$ behind the tool center (when the temperature falls below approximately $420^{\circ} \mathrm{C}$ ). Note that by this time, the grain size has been greatly refined, as this material has passed the pin and has been subject to severe plastic deformation. The predicted grain size at this point was approximately $1 \mu \mathrm{m}$. This very fine grain size provides a large area of grain boundary for heterogeneous nucleation. Note that the grain size evolves (grows) rapidly as the hot material exits behind the pin and so the final grain size does not necessarily represent the grain size at the point where grain boundary precipitation begins. This complex coupling is discussed in more detail elsewhere for the case of AA7449 FSWs [22].

It is predicted that the grain boundary precipitates grow in preference to the (small) re-precipitated $\eta$ phase particles within the grains, which fully dissolve. Finally, at a position $8 \mathrm{~mm}$ behind the tool center, once the temperature falls below $240^{\circ} \mathrm{C}$, it is predicted that fine scale $\eta^{\prime}$ precipitates nucleate within the grains, although the final volume fraction reached by these precipitates is small (less than $20 \%$ of the original fraction) so that the matrix will remain supersaturated in solute at the end of welding (which can lead to natural ageing in the stir zone). The predicted final microstructure therefore consists of a bimodal population of (larger) precipitates formed on the refined grain boundaries (before grain growth) and (smaller) $\eta^{\prime}$ within the grains. Qualitatively, this corresponds closely to the STEM observation of the microstructure in the stir zone. Note that the extensive grain growth that occurs immediately behind the tool may be the reason that the grain boundary nucleated precipitates end up some distance from the final position of the grain boundaries after the weld has fully cooled.

At increasing distance from the weld center, the difference in thermal 
field and deformation lead to a change in the balance of kinetic processes. At a lateral distance $4 \mathrm{~mm}$ from the centerline (Figure 6 (c)), the same basic sequence is predicted, but the predicted volume fraction of grain boundary precipitates is reduced and the predicted fraction of $\eta^{\prime}$ reprecipitation in the grain interior is increased. This is consistent with the SAXS results, which showed an increase in reprecipitated volume fraction behind the tool at $4 \mathrm{~mm}$ compared with the tool centerline.

The reduced grain boundary precipitation at $4 \mathrm{~mm}$ lateral distance is due to a lack of direct stirring in this region, so there is no grain refinement, leading to a much lower grain boundary area per volume than in the SZ. The increase in precipitation within the grains is due to the additional solute available resulting from the reduced fraction of grain boundary precipitation. This trend continues to $7 \mathrm{~mm}$ from the weld center, which is just outside the edge of the shoulder (Fig. 6 (d)). Here, there are only thermal effects, there is no grain refinement, and the fraction of grain interior reprecipitation is predicted to be much larger than the fraction of grain boundary precipitation. The SAXS technique measures an average effective volume fraction in which the (spatial) distribution of precipitates is not considered. The true microstructure is known to be spatially heterogenous and there will be precipitate free zones (PFZs) adjacent to the grain boundaries. Changes in thermal exposure will change the PFZ width but this will be averaged out in the SAXS results. For example, an increase in PFZ width (and no other changes) would lead to a reduction in the effective volume fraction determined by SAXS.

In general, the qualitative predictions of the final microstructure given by the model are consistent with the STEM observations. A quantitative comparison of the particle size distributions in the HAZ ( $7 \mathrm{~mm}$ lateral distance) predicted and measured using both methods is shown in Figure 8. It can be seen that for the precipitates in the grain interior (Figure 8(a)), the mean sizes are in agreement within a factor of two from all techniques. The mean size determined by SAXS is smaller than that determined from STEM and by prediction, but given the complexity of the true microstructures (including heterogeneities) this is considered to be a reasonable level of agreement.

The particle size distribution predicted by the model is narrower than that determined experimentally; this is most probably due to the simplifications inherent in the KWN model, in particular the simple treatment of interfacial energy. The mean grain boundary precipitate size is also well predicted by the model when compared with STEM measurement (Figure 8(b)). The size 
of these precipitates is outside the range probed by the SAXS experiment, so no SAXS results are available for comparison.

The complexity of the precipitate evolution, and in particular the prediction (and STEM observation) that there are often bimodal or even trimodal distributions of precipitates adds to the complexity of interpreting the SAXS results. Fortunately, in most cases, the particles from different distributions are sufficiently separated in size that SAXS data can be interpreted by comparing against a single precipitate population. For example, in the stir zone, it is predicted that there will be larger grain boundary nucleated $\eta$ phase particles and smaller $\eta^{\prime}$ particles formed within the grains. The model predicts that the $\eta^{\prime}$ precipitates in the stir zone have mean radii between $1.3-2.5 \mathrm{~nm}$, whereas the grain boundary $\eta$ particles have a mean radii between $50-80 \mathrm{~nm}$. This means that the grain boundary $\eta$ particles are above the size range analysed by SAXS (maximum radius $20 \mathrm{~nm}$ ), and so the measurements in this range correspond only to the grain interior precipitate population.

A comparison between the precipitate volume fraction measured by SAXS from the weld center to just beyond edge of the tool ( $8 \mathrm{~mm}$ lateral distance) and the model predictions for the $\eta^{\prime}$ phase volume fraction across this region are shown in Figure 9. It can be seen that although the model predictions fall outside the error bars of the SAXS measurement, the agreement is reasonable given the complexity of the problem (predicting precipitation under highly non-isothermal conditions in material undergoing simultaneous deformation). Importantly, both the model and the SAXS measurement show that the volume fraction increases going away from the weld center. This is because at the weld center, the initial small precipitates are fully dissolved and reprecipitate as large grain boundary particles that are not measured by SAXS. At increasing distance, the lower heat input means that there are a greater fraction of small particles (in the range for SAXS detection), either by reprecipitation or reduced coarsening of the pre-existing precipitates. Up to $8 \mathrm{~mm}$ lateral distance the model predicts that this is dominated by reprecipitation of fine particles. Note that both SAXS and the model show that the volume fraction of precipitation in this region is far below (less than half) that in the parent material, meaning that supersaturated solute will remain after welding, which is able to contribute to post-weld natural ageing.

\subsubsection{Predicting Effect of Changing Welding Speed}

The model was also applied to predict the effect of changing the weld speed on the precipitate evolution in the HAZ. The SAXS results demon- 
strated that the effect of welding speed on the minimum precipitate fraction reached in the HAZ becomes more significant as the distance into the HAZ increases (Figure 4). Predictions of the total grain interior precipitate volume fraction for the two extremes of welding speed $\left(2 \mathrm{~mm} \mathrm{~s}^{-1}\right.$ and $\left.8 \mathrm{~mm} \mathrm{~s}^{-1}\right)$ and two lateral positions ( $7 \mathrm{~mm}$ from centerline, just outside shoulder, and $10 \mathrm{~mm}$ from centerline) are shown in Figure 10. As shown in Figure 1, the SAXS measurements were taken along a lateral line perpendicular to the tool center. This corresponds to the point where the maximum temperature, and hence minimum precipitate volume fraction, will be reached in the HAZ. As both the model predictions and SAXS measurements show, even for the slowest welding speed, full dissolution of the initial precipitate population does not occur at any position in the HAZ, although nearest the tool and at the slowest speed (Figure 10(a)), the minimum volume fraction reached is very small. The critical parameter that controls the minimum volume fraction reached at any position is the peak temperature reached. This reduces with increasing lateral distance from the tool shoulder and with increasing welding speed (for a given position). The lower the peak temperature, the less dissolution occurs, and the greater the retained precipitate volume fraction.

For the position nearest to the tool shoulder $(7 \mathrm{~mm})$, both welding speeds are predicted to produce a large amount of precipitate dissolution, such that even for the fastest speed, less than half of the original volume fraction survives. In the case of the slowest speed, the amount of dissolution is large enough and the cooling rate is slow enough to lead to a prediction of extensive re-precipitation on cooling. In the fastest weld, the reduced supersaturation and faster cooling rate are predicted to suppress reprecipitation. Compared with the SAXS measurement, the model appears to overestimate the amount of dissolution at the slowest speed, and underestimate the amount at the fastest speed (Table 2). This suggests further refinement of the model beyond the scope of this work is needed to improve quantitative accuracy. In particular, the simple treatment of interfacial energy inherent in the KWN method is likely to be a limiting factor. However, both SAXS and model predictions qualitatively confirm the same critical point; in the HAZ region close to the tool shoulder most of the initial precipitates dissolve at all welding speeds studied.

Further from the centerline (at $10 \mathrm{~mm}$ ) the effect of welding speed on precipitate volume fraction is different. At the slowest speed, it is predicted that the material is hot enough for long enough to lead to most of the initial precipitate volume fraction being dissolved. This is in agreement with the 
SAXS measurements. However, at the fastest speed, almost no dissolution is predicted, since the time at temperature is insufficient. However, the microstructure is still predicted to be influenced by the welding process through the coarsening of $\eta^{\prime}$ and partial transformation to $\eta$, as shown in Figure 11. Note that the $\eta^{\prime}$ and $\eta$ populations were predicted to have different, but overlapping, size distributions (with predicted mean radii of 1.6 and $2.4 \mathrm{~nm}$ respectively). This makes a quantitative comparison with the SAXS results difficult. However, qualitatively the SAXS results and model show the same trend for the fastest welding speed at $10 \mathrm{~mm}$ lateral distance; in both cases most of the original precipitate volume fraction is retained.

Overall, these predictions are consistent with the SAXS measurements that demonstrated the effect of using a slower welding speed on precipitate dissolution is greater the further the distance from the weld centerline. As the weld speed slows, the thermal field (and hence HAZ) expands, and this leads to dissolution further from the weld center. This explains why a slower speed leads to a wider zone in which a measured reduction in hardness is observed [6].

Finally, it is helpful to make some comments regarding the implications of these results to other $7 \mathrm{xxx}$ friction stir welds. It is important to note that the present weld was performed with a high rotation speed (1300 RPM) and on material in an initially underaged condition with small (and therefore relatively unstable) precipitates. The relatively high fraction of precipitate dissolution measured (and predicted) in the HAZ and reprecipitation in the $\mathrm{HAZ}$ on post-weld cooling is a consequence of this combination of material and process conditions. For 7xxx material welded in a T6 or T7 temper, with a lower heat input, the balance in mechanisms is expected to change. For example, in previous work the present model was applied to welding of AA7150-T6 performed with a rotation speed of 215 RPM [12]. In this case it was predicted that only transformation of metastable $\eta^{\prime}$ and partial redissolution occurs in the HAZ. Precipitation on post-weld cooling in this case was predicted to occur by growth of exisiting particles rather than nucleation of new ones, leading to an overaged microstructure. The balance of mechanisms, especially in the HAZ, is therefore highly sensitive to initial microstructural state and welding conditions and it is incorrect to assume a single microstructural mechanism (e.g. coarsening) is always operating in this region. 


\section{Conclusions}

A novel system capable of performing friction stir welds in a synchrotron X-ray beamline (FlexiStir) has been developed and applied to making insitu measurements of precipitate evolution using small angle X-ray scattering (SAXS) during the welding of an age hardened aluminium alloy (7449-TAF). For the first time, the FlexiStir system has enabled collection of time or position resolved precipitate volume fraction and size data during FSW, which cannot be determined using ex-situ methods. This is essential in understanding the highly dynamic microstructural processes that occur during welding, ultimately controlling the weld performance. In particular, the SAXS measurements have confirmed that extensive reprecipitation occurs behind the tool, but this is very sensitive to the distance from the weld centerline. The following conclusions may be drawn from this work:

- It has been demonstrated that the FlexiStir system combined with small angle X-ray scattering measurements performed using a high energy synchrotron beam-line is capable of tracking the dynamic precipitate evolution that occurs during the friction stir welding of aerospace aluminium alloy 7449-TAF.

- A full interpretation of the results from the FlexiStir system is only possible when combined with the microstructural model, which allows the contribution from different precipitate phases to be deconvoluted.

- It has been shown that for the alloy and welding conditions investigated, full precipitate dissolution occurs in the stir zone (SZ) of the weld. Partial reprecipitation occurs mainly on grain boundaries since the refined grain size in the SZ provides an abundance of grain boundary area for heterogenous nucleation. Supersaturated solute remains in the matrix for post-weld natural ageing.

- Partial precipitate dissolution occurs in the thermomechanically affected zone (TMAZ). On post-weld cooling, partial reprecipitation occurs. A greater fraction of these precipitates form as fine particles within the grains rather than as coarse grain boundary precipitates compared with the SZ. This can be explained by the lack of grain refinement in the TMAZ. 
- The fraction of precipitates dissolved in the heat affected zone (HAZ) depends on the distance from the weld centerline and the tool travel speed. Close to the shoulder, most of the original volume fraction is lost for all welding speeds studied. The effect of welding speed becomes marked as the distance from the centerline increases. A faster welding speed leads to less precipitate dissolution further from the centerline. Even when the volume fraction of precipitates remains relatively unaffected, the model predicts there is still significant coarsening and transformation from $\eta^{\prime}$ to $\eta$ within the HAZ.

\section{Acknowledgements}

The authors would like to acknowledge the support from the Virtual Institute for "Improving Performance and Productivity of Integral Structures through Fundamental Understanding of Metallurgical Reactions in Metallic Joints" (VI-IPSUS). The VI-IPSUS is an initiative of the Helmholtz Association coordinated by the Helmholtz-Zentrum Geesthacht GmbH. Henry Loitz is thanked for his assistance with the beam-line experiments. One of the authors (JDR) is grateful to EPSRC LATEST-2 programme grant (EP/ H020047/1) for financial support for this work. The data used in this study may be obtained by contacting the corresponding author.

[1] W. M. Thomas, E. D. Nicholas, J. C. Needham, M. G. Church, P. Templesmith, International Patent Application No. PCT/GB92/002203 and GB Patent Application No. 9125978.9 (1991).

[2] R. S. Mishra, Z. Y. Ma, Friction stir welding and processing, Mater. Sci. Eng. R 50 (2005) 1-78.

[3] R. Zettler, T. Donath, J. F. dos Santos, J. F. Beckman, D. Lohwasser, Validation of marker material flow in $4 \mathrm{~mm}$ thick friction stir welded al 2024-T351 through computer microtomography and dedicated metallographic techniques, Adv. Eng. Mater. 8 (2006) 487-490.

[4] A. L. Etter, T. Baudin, N. Fredj, R. Penelle, Recrystallization mechanisms in $5251 \mathrm{H} 14$ and $5251 \mathrm{O}$ aluminum friction stir welds, Mater. Sci. Eng. A 445-446 (2007) 94-99. 
[5] A. Sullivan, J. D. Robson, Microstructural properties of friction stir welded and post-weld heat-treated 7449 aluminium alloy thick plat, Mater. Sci. Eng. A 478 (2008) 351-360.

[6] M. Dumont, A. Steuwer, A. Deschamps, M. Peel, P. Withers, Microstructure mapping in friction stir welds of 7449 aluminium alloy using SAXS, Acta Mater. 54 (2006) 4793-4801.

[7] P. Threadgill, Terminology in friction stir welding, Sci. Technol. Weld. Join. 12 (2013) 357-360.

[8] P. A. Colegrove, H. R. Shercliff, CFD modelling of friction stir welding of thick plate 7449 aluminium alloy, Sci. Technol. Weld. Join. 11 (2006) 429-441.

[9] H. Schmidt, J. Hattel, J. Wert, An analytical model for the heat generation in friction stir welding, Modelling Simul. Mater. Sci. Eng. 12 (2004) 143-157.

[10] H. R. Shercliff, M. J. Russell, A. Taylor, T. L. Dickerson, Microstructural modelling in friction stir welding of 2000 series aluminium alloys, Méchanique and Industries 6 (2005) 25.

[11] N. Kamp, A. Sullvan, R. Tomasi, J. D. Robson, Modelling of heterogeneous precipitate distribution evolution during friction stir welding process, Acta Mater. 54 (2006) 2003-2014.

[12] N. Kamp, A. Sullivan, J. D. Robson, Modelling of friction stir welding of 7xxx aluminium alloys, Mater. Sci. Eng. A 446 (2007) 246-255.

[13] A. P. Hammersley, Fit2d v12.012 reference manual v6.0, ESRF user manual (2004).

[14] H. Wang, P. A. Colegrove, J. F. dos Santos, Hybrid modelling of 7449-t7 aluminium alloy friction stir welded joints, Sci. Technol. Weld. Join. 18 (2013) 147-153.

[15] R. Kampmann, R. Wagner, Materials Science and Technology, vol. 5, VCH Weinheim, Germany, 1991. 
[16] J. D. Robson, L. Campbell, Model for grain evolution during friction stir welding of aluminium alloys, Sci. Technol. Weld. Join. 15 (2010) 171-176.

[17] R. A. Carolan, R. G. Faulkner, Grain boundary precipitation of $\mathrm{M}_{23} \mathrm{C}_{6}$ in an austenitic steel, Acta Metall. 36 (1988) 257-266.

[18] M. Dumont, W. Lefebvre, B. Doisneau-Cottignies, A. Deschamps, Characterisation of the composition and volume fraction of $\eta^{\prime}$ and $\eta$ precipitates in an Al-Zn-Mg alloy by a combination of atom probe, small-angle $\mathrm{X}$-ray scattering and transmission electron microscopy, Acta Mater. 53 (2005) 2881-2892.

[19] J. D. Robson, M. J. Jones, P. B. Prangnell, Extension of the n-model to predict competing homogeneous and heterogeneous precipitation in al-sc alloys, Acta Materialia 51 (2003) 1453.

[20] J. Gjønnes, C. J. Simensen, An electron microscope investigation of the microstructure in an aluminium-zinc-magnesium alloy, Acta Metall. $18(881-890)$.

[21] P. B. Prangnell, C. P. Heason, Grain structure formation during friction stir welding observed by the stop action technique, Acta Mater. 53 (2005) 3179-3192.

[22] J. D. Robson and L. Campbell, Microstructural Modelling for Friction Stir Welding of High Strength Aluminum Alloys, Materials Science Forum, 706-709 (2012) 1008-1013.

\section{Tables}

\begin{tabular}{|ccc|}
\hline Speed $/ \mathrm{mm} \mathrm{s}^{-1}$ & SAXS / \% & Model / \% \\
\hline 2 & 17.4 & 0.1 \\
8 & 30.4 & 48.2 \\
\hline
\end{tabular}

Table 2: Minimum measured (SAXS) and predicted (model) total precipitate fraction as a percentage of the initial precipitate fraction at $7 \mathrm{~mm}$ from centerline (heat affected zone edge) for slow $\left(2 \mathrm{mms}^{-1}\right)$ and fast $\left(8 \mathrm{~mm} \mathrm{~s}^{-1}\right)$ welding speeds. 


\section{Figure Captions}

(a)

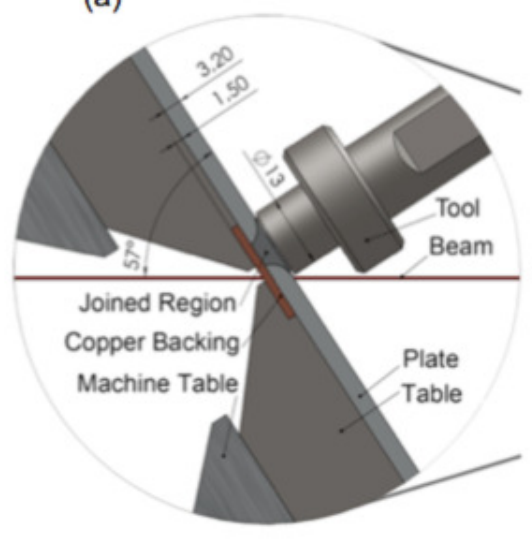

(b)

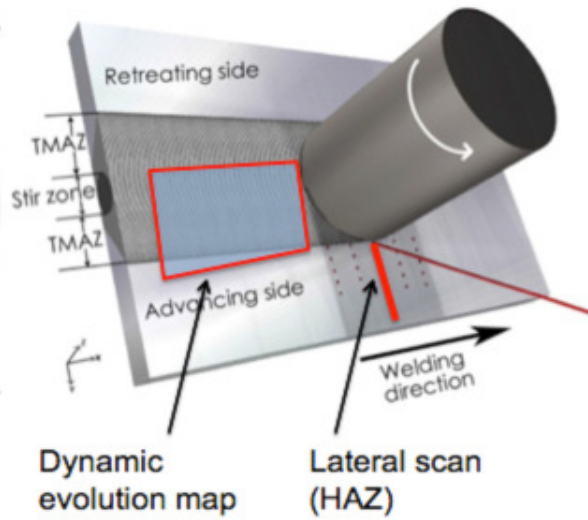

(SZ, TMAZ)

Figure 1: Experimental set up of FlexiStir system (a) Side view, showing configuration of tool, plate, and backing bar. (b) Isometric view showing region analysed to study dynamic precipitate evolution behind the tool and the lateral scan to study precipitate dissolution in the heat affected zone (HAZ) 


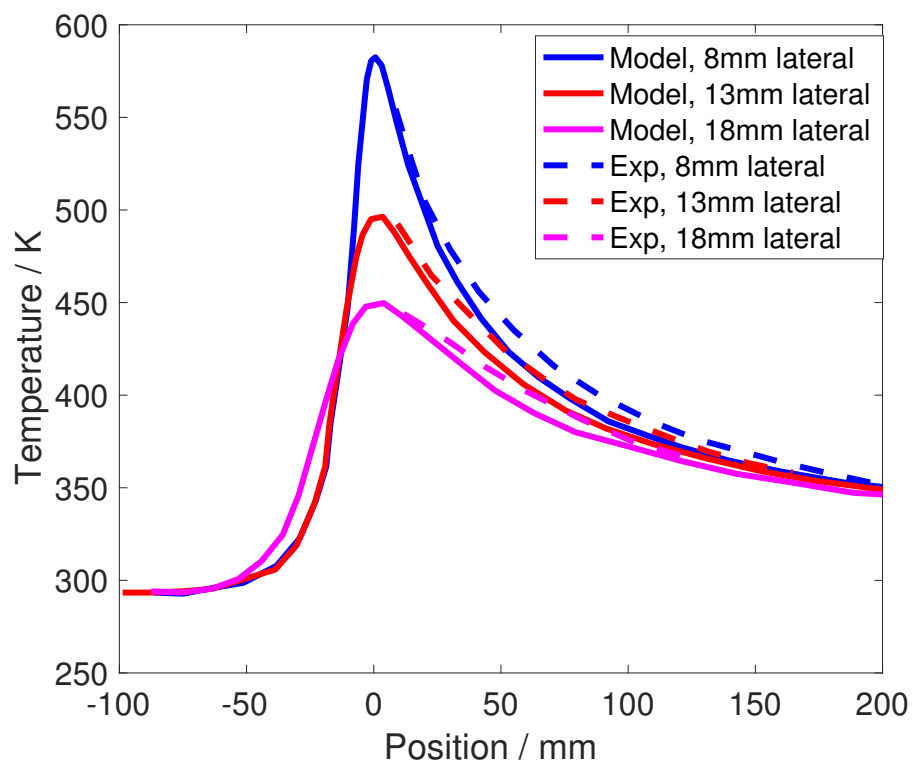

Figure 2: Example thermal predictions of process model compared with thermocouple measurements (welding speed $5 \mathrm{~mm} \mathrm{~s}^{-1}$ ) 


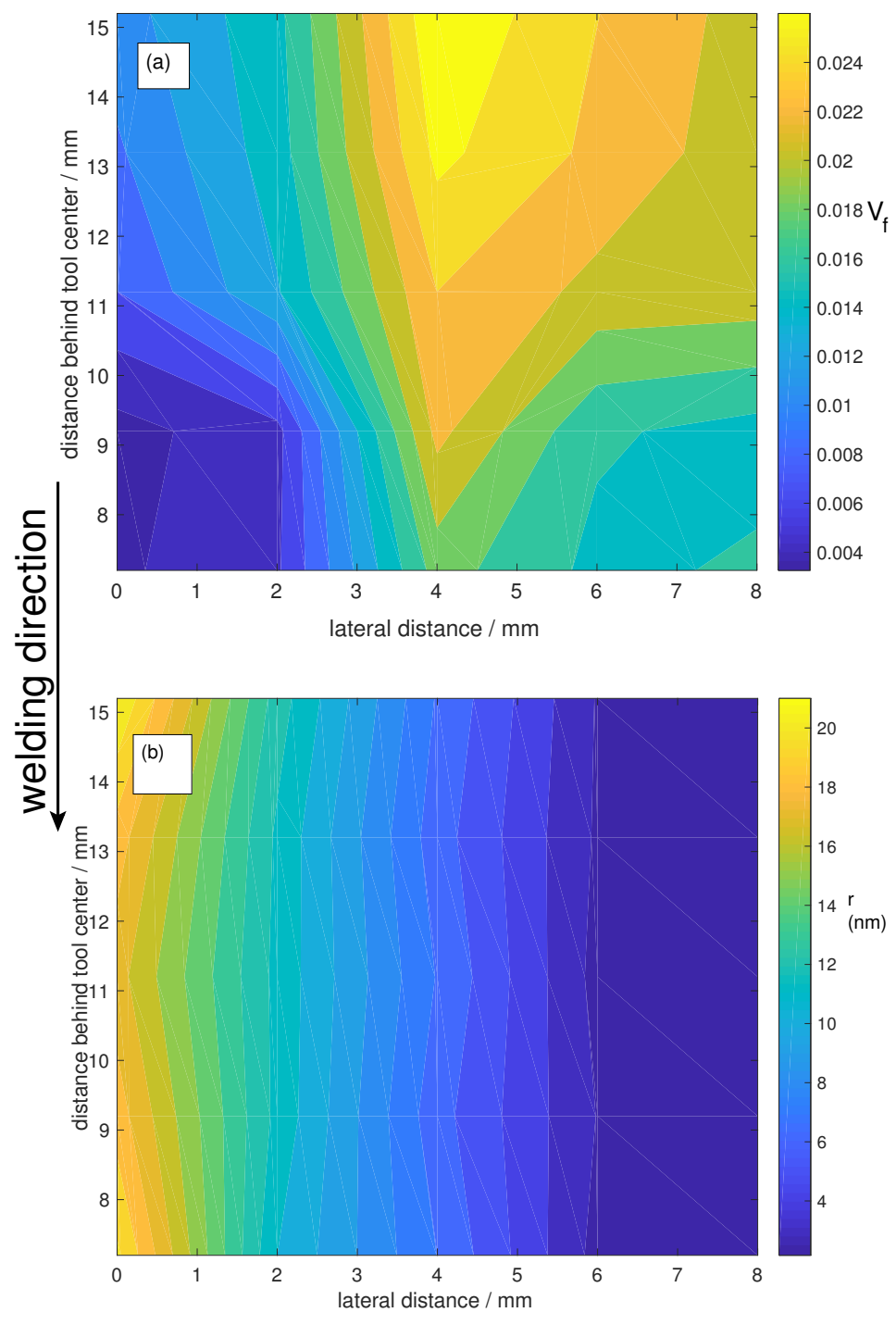

Figure 3: Maps showing the measured evolution of (a) precipitate volume fraction and (b) precipitate radius for the region behind the tool (welding speed $5 \mathrm{~mm} \mathrm{~s}^{-1}$ ) 


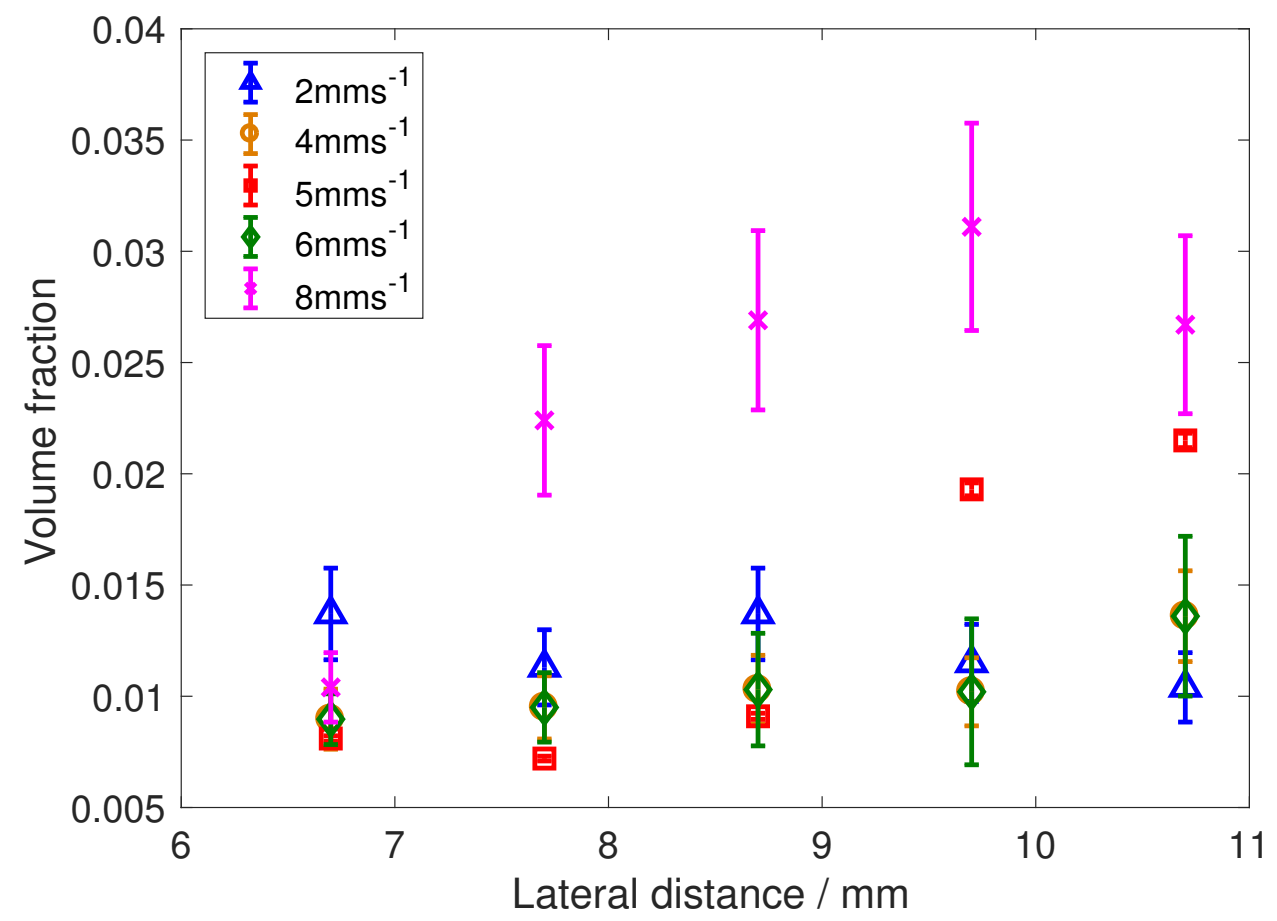

Figure 4: Measured volume fraction of precipitates in the heat affected zone (HAZ) for different welding speeds as a function of distance from the weld centerline for a lateral scan perpendicular to the tool travel direction.

(a)

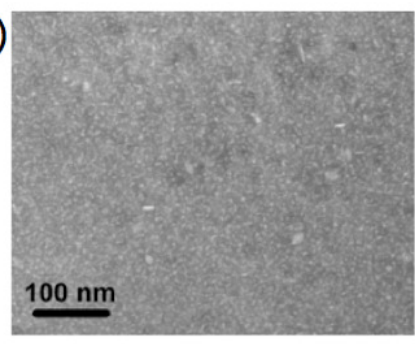

(b)

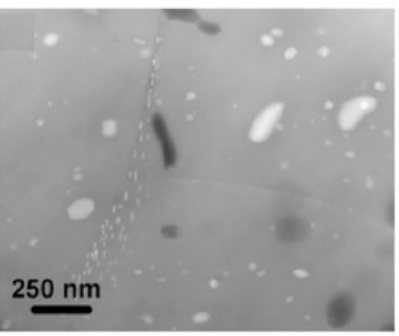

(c)

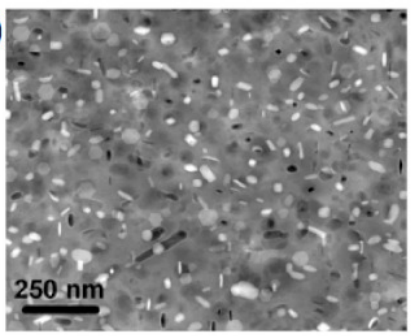

Figure 5: Dark field scanning transmission electron microscopy (STEM) images of the microstructure showing the precipitates present in (a) base material (b) stir zone (c) thermo-mechanically affected zone (welding speed $5 \mathrm{~mm} \mathrm{~s}^{-1}$ ). 

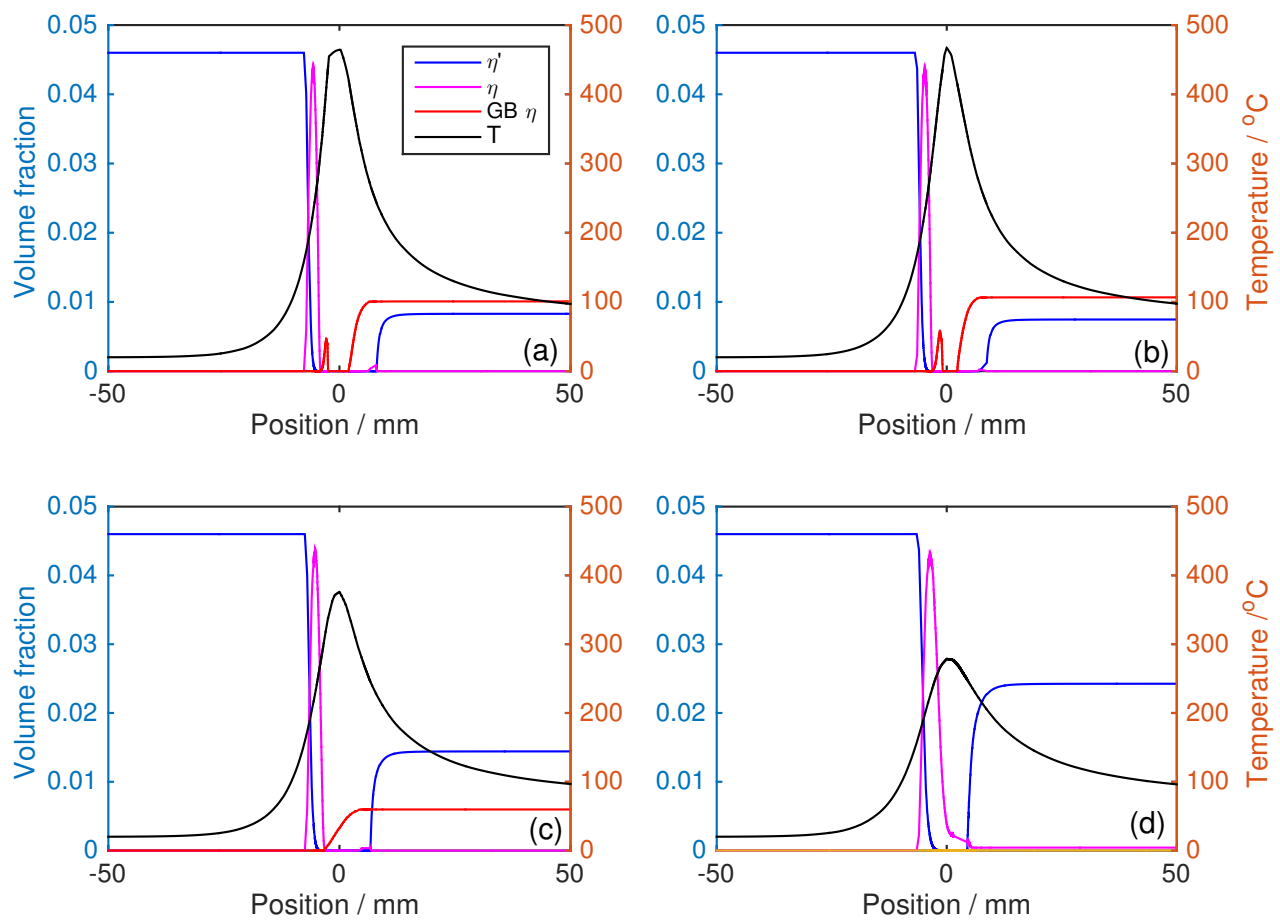

Figure 6: Predicted evolution of precipitate volume fraction as a function of distance ahead or behind the tool center (positive positions are behind the tool center) (a) weld centerline (0 mm lateral position) (b) $2 \mathrm{~mm}$ from centerline, (c) $4 \mathrm{~mm}$ from centerline, (b) $7 \mathrm{~mm}$ from centerline (heat affected zone edge). Welding speed $5 \mathrm{~mm} \mathrm{~s}^{-1}$ 


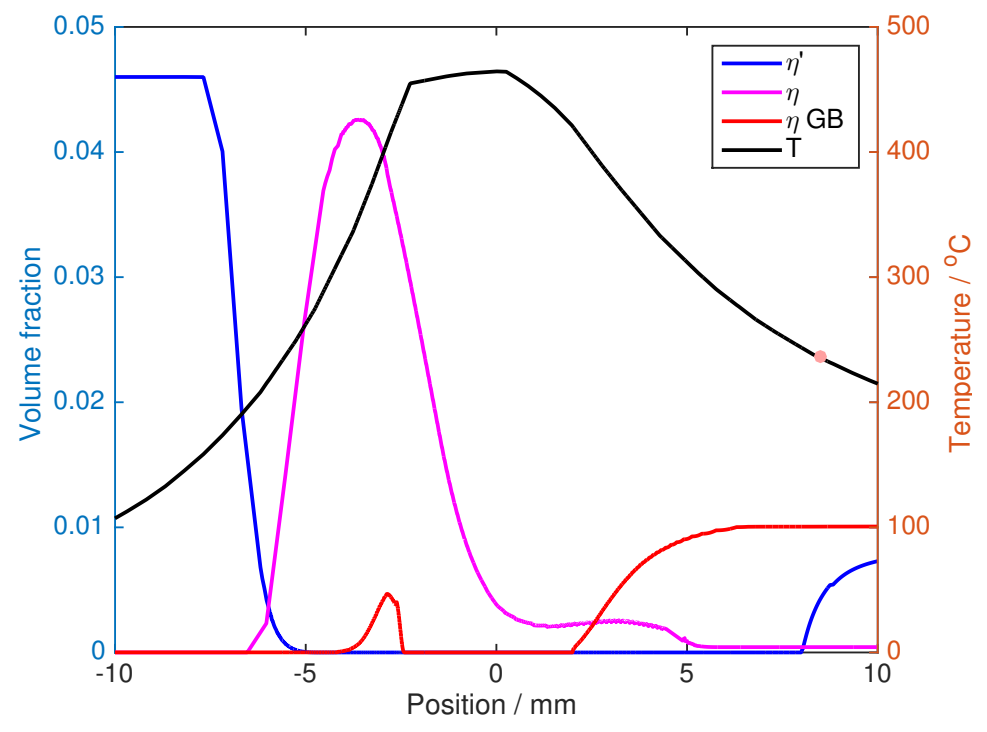

Figure 7: Predicted evolution of precipitate volume fraction at the weld centerline (zoomed in to focus on positions close to the tool center). Welding speed $5 \mathrm{~mm} \mathrm{~s}^{-1}$
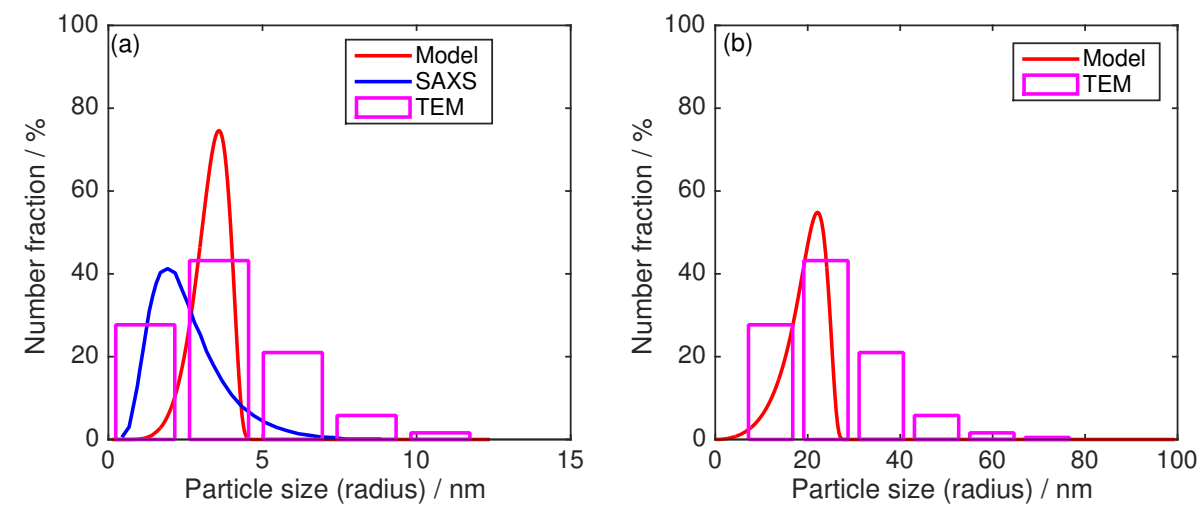

Figure 8: A comparison of the precipitate size distribution measured by SAXS and STEM and predicted by the model for a position $7 \mathrm{~mm}$ from the weld centerline (a) grain interior precipitates, (b) grain boundary precipitates (outside the size range measured by SAXS). 


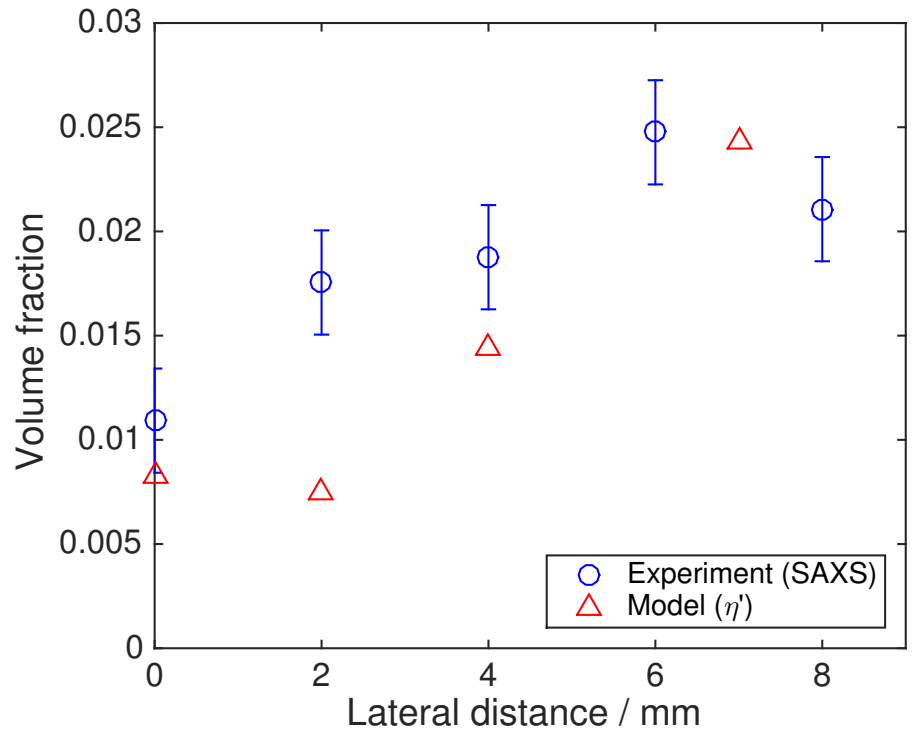

Figure 9: Model prediction and SAXS measurement of the final volume fraction of precipitates during welding (in-situ) as a function of lateral distance from the weld centerline. Welding speed $5 \mathrm{~mm} \mathrm{~s}^{-1}$. 

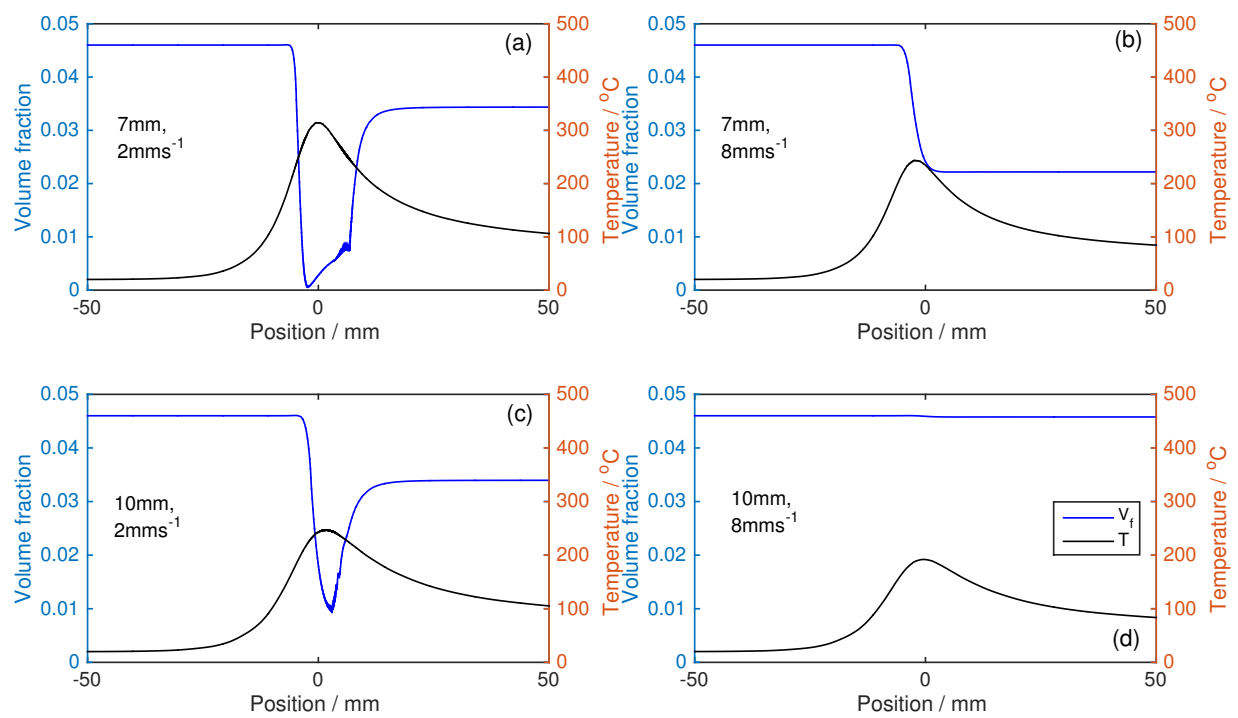

Figure 10: Model predictions of total precipitate volume fraction at $7 \mathrm{~mm}$ lateral distance from centerline (HAZ close to tool) for welding speeds of (a) $2 \mathrm{~mm} \mathrm{~s}^{-1}$ and (b) $8 \mathrm{~mm} \mathrm{~s}^{-1}$. At $10 \mathrm{~mm}$ lateral distance from centerline for welding speeds of (c) $2 \mathrm{~mm} \mathrm{~s}^{-1}$ and (d) $8 \mathrm{~mm} \mathrm{~s}^{-1}$. The $\mathrm{x}$-axis (position) refers to the position in the feed direction, with negative positions ahead of the tool center and positive positions behind the tool center. 


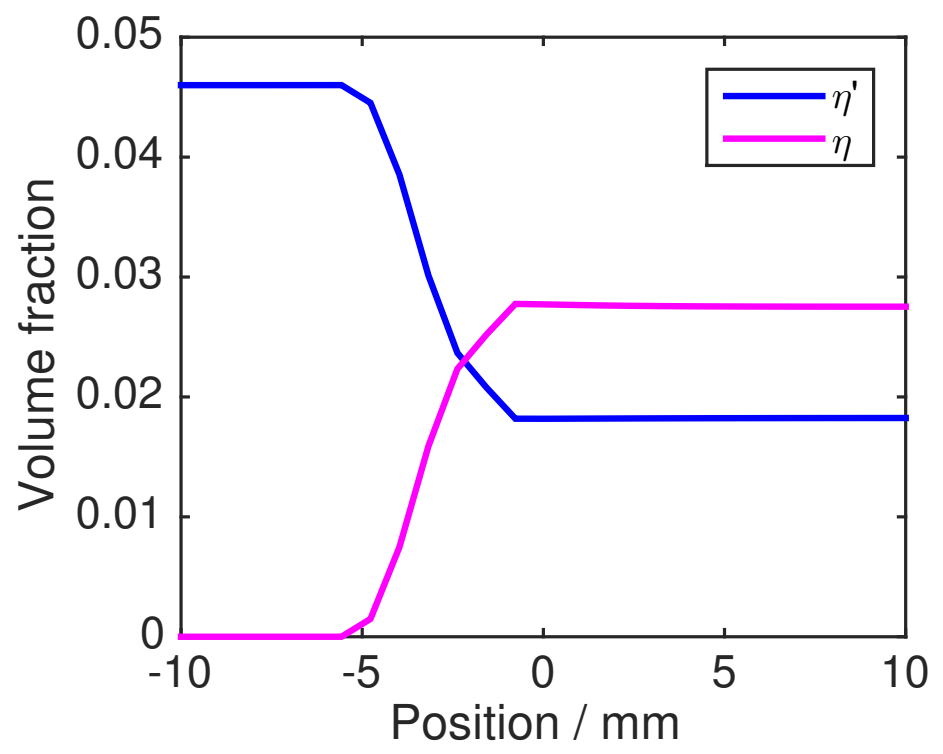

Figure 11: Model predictions showing phase transformations predicted at $10 \mathrm{~mm}$ lateral distance from weld centerline for a welding speed of $8 \mathrm{~mm} \mathrm{~s}^{-1}$. 